\title{
A Novel Electromagnetic Mill Promoted Mechanochemical Solid-State Suzuki-Miyaura Cross-Coupling Reactions: Ultra-Low Catalyst Loading without Molecular Dispersants
}

Xin Li

Yunxia Liu

Lizhi Zhang

Yunhui Dong

Qing Liu

Daopeng Zhang

Lei Chen

Hui Liu ( $\square$ huiliu1030@163.com )

Shandong university of technology

Zengdian Zhao

Article

Keywords: Suzuki-Miyaura Cross-Coupling, Solid-State, Electromagnetic Mill, Mechanochemistry, Solvent-

Free

Posted Date: September 3rd, 2021

DOI: https://doi.org/10.21203/rs.3.rs-870617/v1

License: (c) (1) This work is licensed under a Creative Commons Attribution 4.0 International License.

Read Full License 


\section{Abstract}

The Nobel-prize-winning Suzuki-Miyaura cross-coupling(SMC) is a practical and attractive strategy for the construction of $\mathrm{C}-\mathrm{C}$ bonds in both academic and industrial settings. However, the development of solidstate SMC reactions remains extremely scarce. Herein, we report the first electromagnetic mill(EMM) promoted solid-state SMC reaction using ultra-low palladium loading $(0.05 \mathrm{~mol} \%)$ without any molecular dispersants. This protocol exhibits substantially broadened substrate scope, good functional groups tolerance and efficient gram-scale synthesis, especially, provides relative high yields. The utility of this strategy was exemplified in the modification of photoluminescence molecules, cross-coupling of slightly soluble compound and synthesis of several important bioactive molecules. Furthermore, the XPS analyses on the oxidation state changes of palladium catalyst suggest the involvement of $\mathrm{Pd}^{\prime}$ intermediate which might be the active catalytic species. This solvent-free solid-state EMM-SMC was potential developed into industrially attractive and environmentally friendly routes, and the EMM system developed in this study could unlock broad areas of chemical space for solvent-free solid-state metalcatalyzed syntheses of valuable targets in various scientific fields.

\section{Main Text}

Historically, most of the organic transformations adopt solution-based methods, in which solvent are essential to dissolve the reactants and catalysts. More generally, solvent waste in the pharmaceutical industry and fine chemicals industry led to a formidable challenge for the sustainability of chemical synthesis; ${ }^{1,2}$ because an estimated $85 \%$ of waste by mass is attributable to organic solvent used in any organic reactions. ${ }^{3-6}$ Most organic solvents are toxic and easy to catch fire or explode, resulting in huge security risks in the production process. Notably, solvent recycling system have been well established to reduce solvent waste effectively, however, it is still wasteful of fossil-derived materials, environmentally problematic, hazardous and energy-demanding with regard to solvent production, purification and recycling ${ }^{7}$. Therefore, it is extremely desirable to develop green and sustainable synthetic technique.

The best solution for the solvent issue is to avoid using any harmful organic solvent. Therefore, solidstate organic reactions have attracted considerable interest in a variety of research areas as cleaner and sustainable synthetic alternatives ${ }^{4-6,8-11}$. Furthermore, solid-state reactions are particularly suitable for the poorly soluble substrates in common organic solvents ${ }^{8,11-13}$. However, the organic molecules are arranged tightly and regularly, leading to poor mixing efficiency of the reactants and/or catalysts. Thus, to develop highly efficient solid-state organic transformation is of great interest in synthetic chemistry and still remains challenging.

'Mechanochemistry' refers to transformations, normally of solids, induced by mechanical energy, such as by grinding, milling, pulling, shearing and sonication ${ }^{14}$. Since Ostwald proposed the term mechanochemistry in 1887, mechanochemical synthesis has been extensively investigated in polymer chemistry ${ }^{15}$, materials science ${ }^{16,17}$ and inorganic synthesis ${ }^{18}$. However, the application of 
mechanochemistry to organic transformations is more recent ${ }^{19-41}$. So far, most of the examples are focusing on grinding or milling, and the process might promote the reactivity by ensuring thorough mixing and agitation of reactants, particle comminution down to nanometer sizes and creation of activated (amorphous) high-energy phases or zones of high temperature and pressure, which could not be reached in conventional stirring ${ }^{42,43}$.

The Nobel-prize-winning Suzuki-Miyaura cross-coupling(SMC) is a practical and attractive strategy for the construction of $\mathrm{C}-\mathrm{C}$ bonds in both academic and industrial settings ${ }^{44-47}$. More than $60 \%$ of the $\mathrm{C}-\mathrm{C}$ bond is constructed via SMC in medicinal chemistry ${ }^{48}$. Importantly, the classic asymmetric biaryl compounds constructed via SMC are an extensive structural scanfold in pharmaceuticals ${ }^{45,49-52}$. Conventionally, SMC reactions are performed in organic solvents, however, the solvent free reactions, especially for solid-state couplings, have remained extremely scarce. So far, the limited number of mechanochemical conditions are using ball milling 19,22,25,53-58 (Figure 1A). Since 2000, some progresses in solvent-free SMC reactions were reported, and various additives were applied to inhibit aggregation of the catalysts and substrate, such as $\mathrm{NaCl}, \mathrm{AgNO}_{3}$, methanol, $\mathrm{H}_{2} \mathrm{O}, \mathrm{TEA}, \mathrm{Al}_{2} \mathrm{O}_{3}$, chitosan and so on, $54-57,59$ 61 however, the homocoupling issue and limited substrates scope were still needed to figure out.

In addition, the scope of substrates is significantly restricted to electrondefcient aryl halides with low conversion rates. Furthermore, liquid-assisted grinding (LAG) by using a small amount of solvent, has emerged as a common strategy for solid-state reactions. Notably, Ito group demonstrated an olefinaccelerated solid-state SMC reaction using ball milling in 2019 (Figure 1B-1) ${ }^{62}$. They find that olefin additives could act as efficient molecular dispersants to inhibit the deleterious aggregation of palladium catalyst in solid state reactions ${ }^{63}$. Very recently, Ito et. al provide an extremely fast and highly efficient method for cross-coupling reactions of insoluble aryl halides with large polyaromatic structures via a high-temperature ball-milling technique(Figure 1B-2) ${ }^{64}$. Both 1,5-cod and $\mathrm{H}_{2} \mathrm{O}$ play important roles in this transformations. However, it is still challenging to realize solvent free strategies for solid-state organic reactions avoiding any liquid additives due to the poor mixing efficiency and deleterious aggregation of reactants and/or catalysts. Thus we sought to design a new concept to solve this issue in solid-state SMC.

The electromagnetic mill(EMM) is a novel grinding device, using small ferromagnetic particles as the grinding media in a rotating electromagnetic field ${ }^{65}$. The basic elements of the EMM are inductor of rotating magnetic field and placed in its axis tube, serving as a working chamber. Unlike the conventional ball mills, the mill housing is stationary while the grinding takes place in the working chamber using some small ferromagnetic rods to move as grinding media. The movement of ferromagnetic rods is caused by the action of the vortex electromagnetic field. The effectiveness and efficiency of the EMM process is dependent on the size parameters of the rods and the speed and intensity of the rotating electromagnetic field. So far, the EMM is only utilized in shredding of the raw material and ultra-fine comminution. ${ }^{68-71}$ 
Considering on the issue of low reaction efficiency due to aggregation in solid state, we design and develop a new EMM equipment for solid-state coupling reactions, which might potentially solve this problem. Herein, we report the first EMM promoted solid-state SMC reaction using ultra-low catalyst loading without molecular dispersants (Figure 1B-3).

We initially conducted a study to optimize the EMM promoted SMC (EMM-SMC) reaction using 1-(4bromophenyl)ethan-1-one(1a) and (4-methoxyphenyl)boronic acid(2a). Reactions were conducted in a electromagnetic mill in a flat bottom flask $(10 \mathrm{~mL}$ ) (or in a stainless-steel milling jar as shown in Fig. 1C) at $50 \mathrm{~Hz}$ using ferromagnetic rods (diameter: $0.35 \mathrm{~mm}$, long: $5 \mathrm{~mm}$ ). First of all, we focused on a highperformance $\mathrm{Pd}(\mathrm{OAc})_{2}$ /DavePhos catalyst system that has been reported by lto and co-workers using ball milling ${ }^{17}$, notably, without any liquid-assisted grinding (LAG), 1-(4'-methoxy-[1,1'-biphenyl]-4-yl)ethan1-one (3a) was obtained in $82 \%$ within 3 hour (Entry 1, Table 1). The highly catalytic efficiency inspired us to decrease the catalyst loading, interestingly, the yield of 3a was increased to $93 \%$ with $0.5 \mathrm{~mol} \%$ $\mathrm{Pd}(\mathrm{OAc})_{2}$ loading. Further to decrease the loading amount of $\mathrm{Pd}(\mathrm{OAc})_{2}$ to $0.1 \mathrm{~mol} \%$ and $0.05 \mathrm{~mol} \%$, the coupling product was obtained in 95\% (Entries 2-3). However, the yields decreased sharply with 0.02 mol\% or $0.01 \mathrm{~mol} \%$ loading of $\mathrm{Pd}(\mathrm{OAc})_{2}$. Subsequently, bases such as $\mathrm{K}_{2} \mathrm{CO}_{3}, \mathrm{Cs}_{2} \mathrm{CO}_{3}, \mathrm{KOAc}$ and $\mathrm{KF}$, were investigated and KF could improve the yield to $97 \%$ (Entries 7-10). Next, a variety of ligands were examined, however, no better yields was obtained (Entries 11-17). Furthermore, we attempted different catalysts such as $\mathrm{PdCl}_{2}, \mathrm{Pd}(\mathrm{dppf}) \mathrm{Cl}_{2}, \mathrm{Pd}_{2}(\mathrm{dba})_{3}, \mathrm{Pd}(\mathrm{dba})_{2}$ and $\mathrm{PdCl}_{2}(\mathrm{MeCN})_{2}$ (Entries 18-22), delightfully, the corresponding products 3 a was formed in quantitative yields when $\mathrm{PdCl}_{2}(\mathrm{dppf}$ ) was utilized and the reaction time was shorted to 1 hour ( $99 \%$, entry 19$)$.

To explore the scope of the solid-state SMC reaction, a variety of solid aryl halides and arylboronic acid was investigated (Table 2). The reaction of 1-(4-bromophenyl)ethan-1-one(1a) with o-methoxyboronic acid (2b) proceeded to provide the desired coupling product $3 \mathrm{~b}$ in $92 \%$ yield which is slightly lower than with $p$-methoxyboronic acid (2a). Both unsubstituted (2c) or alkyl substituted arylboronic acid (o-Me: $2 \mathrm{~d}$, $p$-tBu: 2e, 2,4,6-tri-methyl: 2f) were coupled in high yields under the optimized conditions (3c-3f).

Arylboronic acid containing $\mathrm{OCF}_{3}$ group also provided the corresponding products in $85 \%$ yield $(3 \mathrm{~g})$. The developed conditions were also applied to the arylboronic acid bearing halides (2-F, 2-Cl, 4-F, 2,4-di-F, 3,4di-Cl, 3,5-di-F and 3,5-di-Cl), which afforded the desired products in good to high yields (3h-3n: 71\%-91\%). Arylboronic acid with strong electron-withdrawing group worked very well to deliver the coupling molecule in both $79 \%$ (3o and $3 p)$. Furthermore, other aromatic cores such as coumarone (2q), oxydibenzene (2r), and naphthalene (2s and $2 \mathrm{t}$ ), efficiently formed the corresponding products in $73 \%-91 \%$ (3q-3t). The coupling of 4-bromobenzonitrile with boronic acid bearing 1-phenylnaphthalene (2u) 4-phenylmorpholine (2v) and (4-propylcyclohexyl)benzene, performed very well to afford the desired molecules in moderate to good yields (3u-3w). Notably, the introduction of $1,1^{\prime}: 3^{\prime}, 1^{\prime \prime}$-terphenyl also worked smoothly to deliver $3 x$ in $67 \%$ yield.

Subsequently, we turned our attention to the scope of aryl bromides (Table 2b). Simple aryl bromides bearing electron-withdrawing groups such as cyano, aldehyde, nitro, carbonyl and chloro groups provided 
the desired products (4a-4e) in good to high yield $(64 \%-92 \%)$. The strong electron-donating group substituted aryl bromides such as 2-bromo-4,6-dimethylaniline and 4-bromo-N,N-dimethylaniline proceeded smoothly to furnish the coupling products $4 \mathrm{f}$ and $4 \mathrm{~g}$ in $75 \%$ and $72 \%$ respectively. The $p$ terphenyl and 2-phenylnaphthalene derivates $4 \mathrm{~h}$ and $4 \mathrm{i}$ were obtained efficiently under the standard conditions (82\% and 93\%). (4-Bromophenyl)(phenyl)methanone and 5-bromo-2,3-dihydro-1H-inden-1-one coupled with $p$-bromoacetophenone to afford $4 \mathrm{j}$ and $4 \mathrm{k}$ in high yields ( $84 \%$ and $85 \%$ ). In addition, aryl bromides bearing thiophene, dibenzothiophene, 2-acetylpyridine or indole motif(Core of various intermediates for drugs and OLED), produced the correspinding products in moderate to high yields (4I$4 p)$. Then the introduction of multi-aromatic scafford to boronic acid could also proceed efficiently to produce the corresponding compounds in $62 \%-81 \%$ yield ( $4 q-4 t)$. Furthermore, some aryl iodides were also investigated which delivered the corresponding products in good yields (5a-5c). Especially, the unprotected phenol could survive very well under the standard conditions (5a-5b).

Table 1. Optimization Study on the EMM Promoted SMC Reaction. 
<smiles>CC(=O)c1ccc(Br)cc1</smiles>

1a

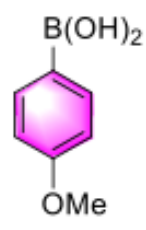

2a

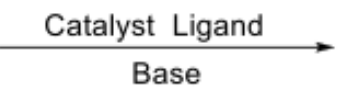

Electromagnetic mill, $\mathrm{t}$

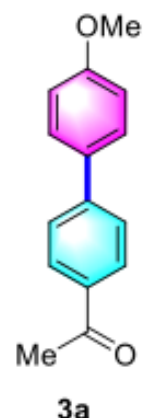

3a

\begin{tabular}{|c|c|c|c|c|c|}
\hline Entry & Catalyst & Ligand & Base & time/h & Yield $/ \%^{\text {b }}$ \\
\hline 1 & $\mathrm{Pd}(\mathrm{OAc})_{2}(3 \mathrm{~mol} \%)$ & DavePhos & CsF & 3 & 82 \\
\hline 2 & $\mathrm{Pd}(\mathrm{OAc})_{2}(0.5 \mathrm{~mol} \%)$ & DavePhos & CsF & 3 & 93 \\
\hline 3 & $\mathrm{Pd}(\mathrm{OAc})_{2}(0.1 \mathrm{~mol} \%)$ & DavePhos & $\mathrm{CsF}$ & 3 & 95 \\
\hline 4 & $\mathrm{Pd}(\mathrm{OAc})_{2}(0.05 \mathrm{~mol} \%)$ & DavePhos & $\mathrm{CsF}$ & 3 & 95 \\
\hline 5 & $\mathrm{Pd}(\mathrm{OAc})_{2}(0.02 \mathrm{~mol} \%)$ & DavePhos & $\mathrm{CsF}$ & 3 & 56 \\
\hline 6 & $\mathrm{Pd}(\mathrm{OAc})_{2}(0.01 \mathrm{~mol} \%)$ & DavePhos & CsF & 3 & 32 \\
\hline 7 & $\mathrm{Pd}(\mathrm{OAc})_{2}(0.05 \mathrm{~mol} \%)$ & DavePhos & $\mathrm{K}_{2} \mathrm{CO}_{3}$ & 3 & 76 \\
\hline 8 & $\mathrm{Pd}(\mathrm{OAc})_{2}(0.05 \mathrm{~mol} \%)$ & DavePhos & KOAC & 3 & 73 \\
\hline 9 & $\mathrm{Pd}(\mathrm{OAc})_{2}(0.05 \mathrm{~mol} \%)$ & DavePhos & $\mathrm{Cs}_{2} \mathrm{CO}_{3}$ & 3 & 50 \\
\hline 10 & $\mathrm{Pd}(\mathrm{OAc})_{2}(0.05 \mathrm{~mol} \%)$ & DavePhos & KF & 3 & 97 \\
\hline 11 & $\mathrm{Pd}(\mathrm{OAc})_{2}(0.05 \mathrm{~mol} \%)$ & dppf & KF & 3 & 86 \\
\hline 12 & $\mathrm{Pd}(\mathrm{OAc})_{2}(0.05 \mathrm{~mol} \%)$ & xphos & KF & 4 & 84 \\
\hline 13 & $\mathrm{Pd}(\mathrm{OAc})_{2}(0.05 \mathrm{~mol} \%)$ & $\mathrm{PCy}_{3}$ & KF & 5 & 73 \\
\hline 14 & $\mathrm{Pd}(\mathrm{OAc})_{2}(0.05 \mathrm{~mol} \%)$ & $\mathrm{PPh}_{3}$ & KF & 5 & 88 \\
\hline 15 & $\mathrm{Pd}(\mathrm{OAc})_{2}(0.05 \mathrm{~mol} \%)$ & PhDavePhos & KF & 3 & 81 \\
\hline 16 & $\mathrm{Pd}(\mathrm{OAc})_{2}(0.05 \mathrm{~mol} \%)$ & Ruphos & KF & 3 & 82 \\
\hline 17 & $\mathrm{Pd}(\mathrm{OAc})_{2}(0.05 \mathrm{~mol} \%) \quad \frac{1}{\mathrm{p}}$ & $\begin{array}{l}\text { 1,1'-Bis(diisopropyl- } \\
\text { phosphino)ferrocene }\end{array}$ & KF & 3 & 79 \\
\hline 18 & $\mathrm{PdCl}_{2}(0.05 \mathrm{~mol} \%)$ & DavePhos & KF & 1 & 79 \\
\hline 19 & $\mathrm{Pd}(\mathrm{dppf}) \mathrm{Cl}_{2}(0.05 \mathrm{~mol} \%)$ & DavePhos & KF & 1 & 99 \\
\hline 20 & $\mathrm{Pd}_{2}(\mathrm{dba})_{3}(0.05 \mathrm{~mol} \%)$ & DavePhos & KF & 3 & 79 \\
\hline 21 & $\mathrm{Pd}(\mathrm{dba})_{2}(0.05 \mathrm{~mol} \%)$ & DavePhos & KF & 3 & 56 \\
\hline 22 & $\mathrm{PdCl}_{2}(\mathrm{MeCN})_{2}(0.05 \mathrm{~mol} \%)$ & DavePhos & KF & 1 & 90 \\
\hline 23 & $\mathrm{Pd}(\mathrm{dppf}) \mathrm{Cl}_{2}(0.05 \mathrm{~mol} \%)$ & - & KF & 1 & 85 \\
\hline
\end{tabular}

a Conditions: $1(1.0 \mathrm{mmol}), 2(1.2 \mathrm{mmol}),[\mathrm{Pd}] /$ ligand $(1: 1.5)$, base $(3.0 \mathrm{mmol})$, in a flat bottom flask $(10 \mathrm{~mL})$ with ferromagnetic rods $(5 \mathrm{~g})$, EMM $50 \mathrm{~Hz}$. 'Isolated yields

Table 2. Substrate Scope of Solid-State EMM-SMC Reaction. ${ }^{\text {a,c }}$ 


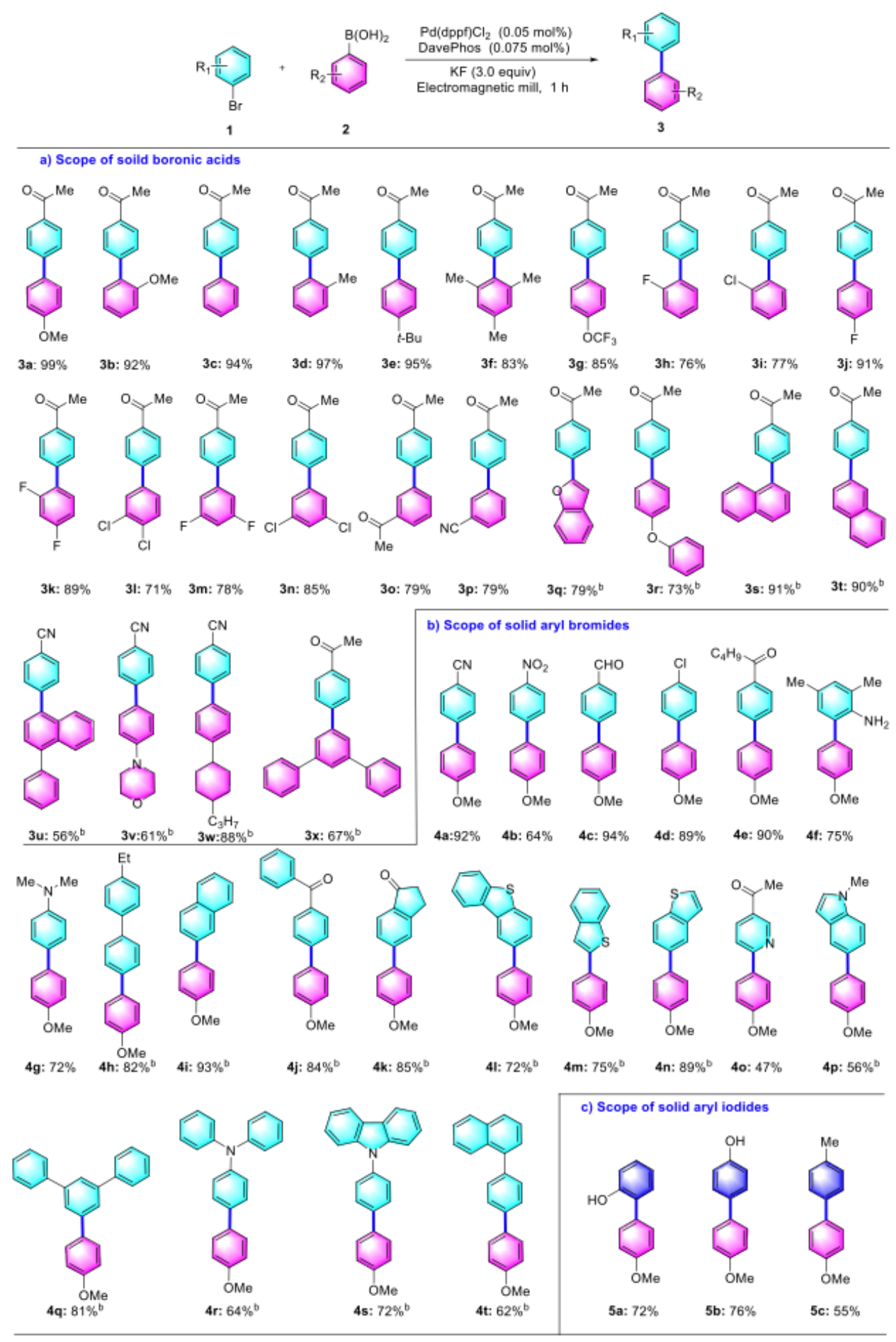

"Conditions: 1 ( $1.0 \mathrm{mmol}), 2(1.2 \mathrm{mmol}), \mathrm{Pd}(\mathrm{dppf}) \mathrm{Cl}_{2}(0.0005 \mathrm{mmol})$, DavePhos $(0.00075 \mathrm{mmol}), \mathrm{KF}(3.0 \mathrm{mmol})$, in a flat bottom flask (10 mL) with ferromagnetic rods $(5 \mathrm{~g})$, EMM $50 \mathrm{~Hz}, 1 \mathrm{~h}$. ${ }^{6}$ Reaction time: $3 \mathrm{~h}$. ' Isolated yield.

Table 3. The Modification of Photoluminescence Molecules via EMM-SMC. ${ }^{a}$ 

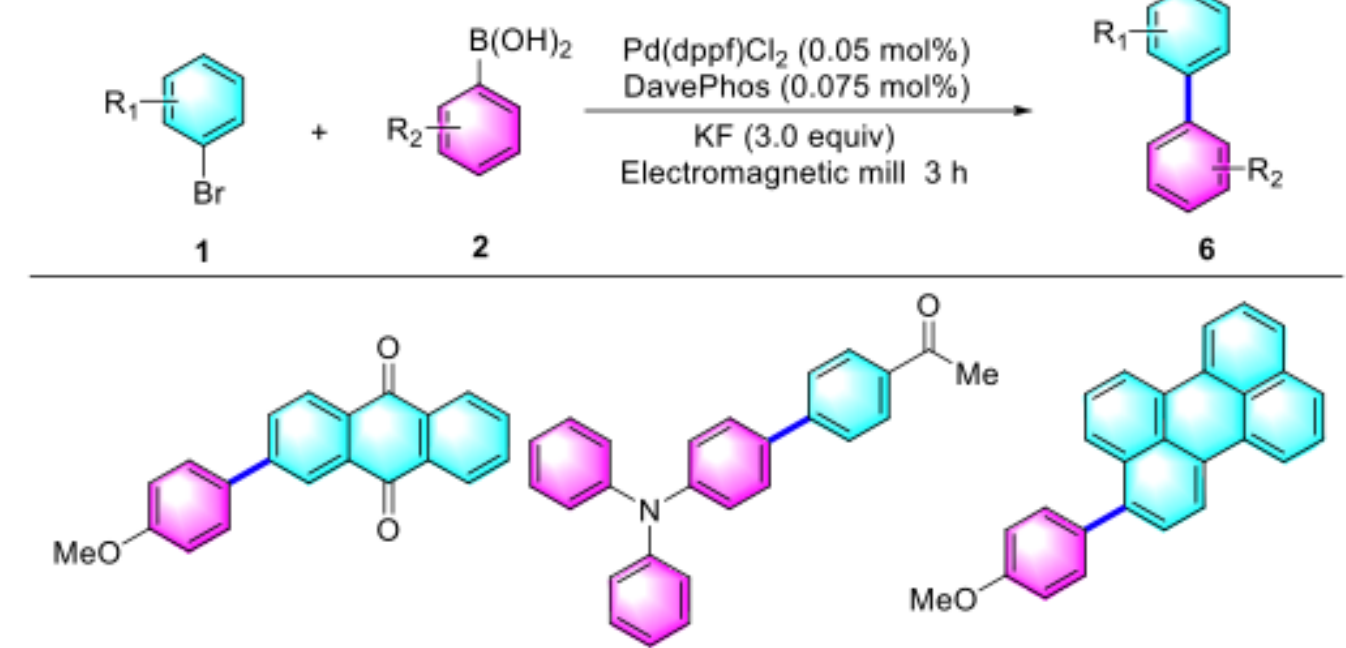

$6 a: 95 \%^{\mathrm{b}}$

6b: $58 \%{ }^{\mathrm{b}}$

$6 c: 76 \%^{b}$

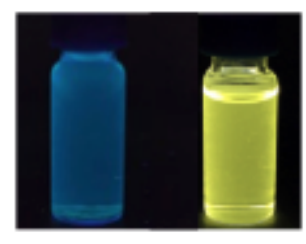

$1-6 a \quad 6 a$
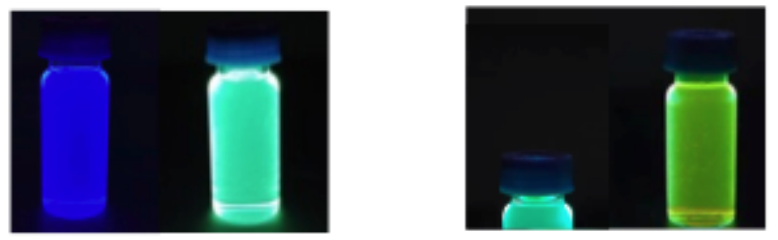

$2-6 b \quad 6 b$

$1-6 c \quad 6 c$

aIsolated yield. b Conditions: 1-6 (1.0 mmol), 2-6 (1.2 mmol), $\mathrm{Pd}$ (dppf) $\mathrm{Cl}_{2}$ (0.0005 mmol), DavePhos (0.00075 mmol), KF(3.0 $\mathrm{mmol})$, in a flat bottom flask $(10 \mathrm{~mL})$ with ferromagnetic rods $(5 \mathrm{~g})$, $50 \mathrm{~Hz}, 3 \mathrm{~h}$.

Table 4. Solid-State SMC Reactions of Slightly Soluble Compound. ${ }^{a}$ 


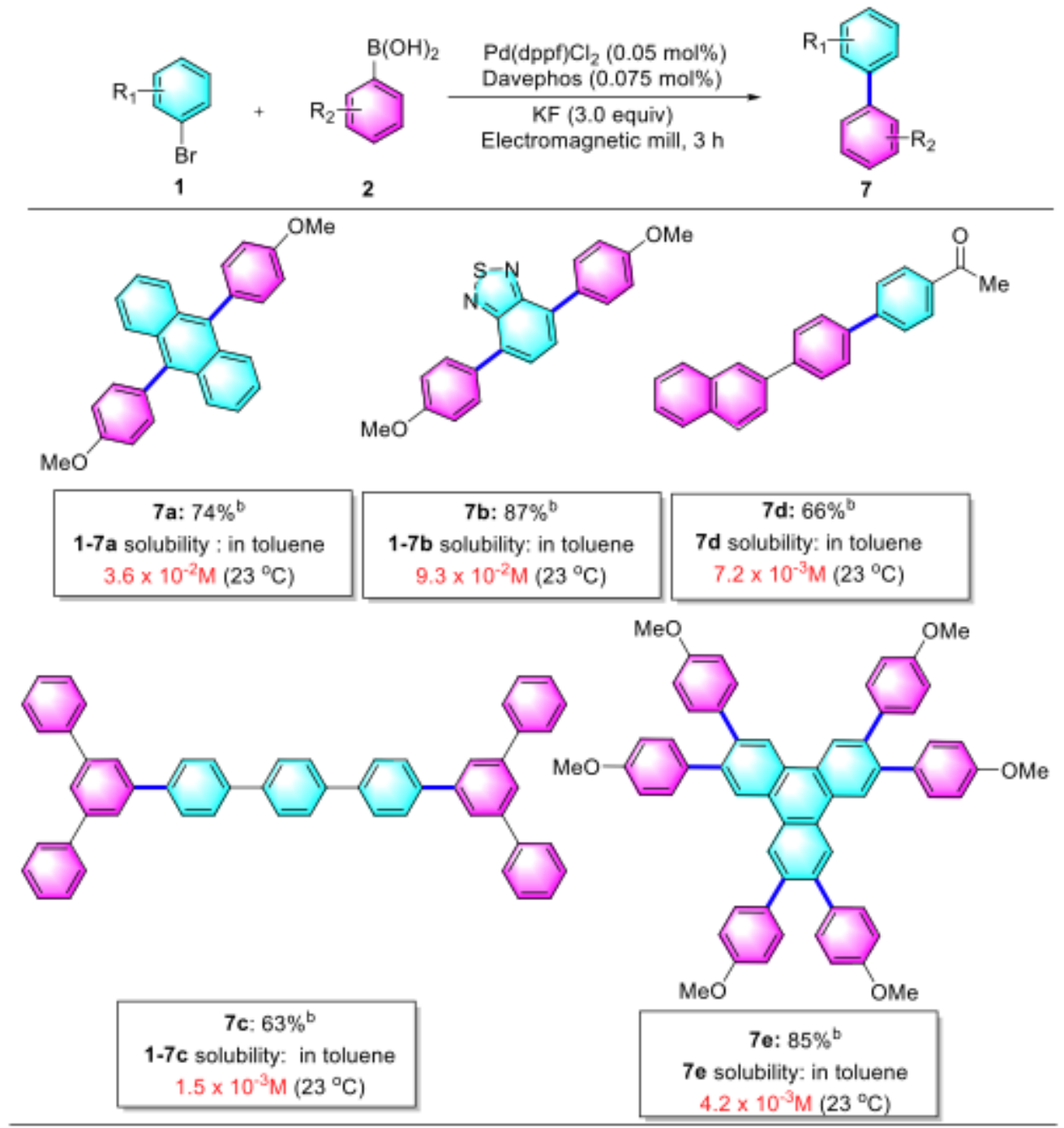

assolated yield. b Conditions: 1-7 (1.0 mmol), 2-7 (1.2 mmol), $\mathrm{Pd}(\mathrm{dppf}) \mathrm{Cl}_{2}$ (0.0005 mmol), DavePhos (0.00075 mmol), KF (3.0 $\mathrm{mmol})$, in a flat bottom flask $(10 \mathrm{~mL})$ with ferromagnetic rods $(5 \mathrm{~g})$, EMM, $50 \mathrm{~Hz}, 3 \mathrm{~h}$.

To further investigate the functional group compatibility and practicality of the developed EMM-SMC, it was used to the modification of photoluminescence molecules. The scaffords of photoluminescence molecules bearing anthracene-9,10-dione, triphenylamine, dibenzopyrrole or perylene worked smoothly to generate the corresponding molecules in good to excellent yields(6a: $95 \%, 6 \mathrm{~b}: 58 \%$ and $6 \mathrm{c}: 76 \%$ ) (Table 3 ). As shown at the bottom of table 3 , the fluorescence of the core scaffolds could be regulated efficiently via EMM-SMC reaction, such as introducing anisole group to anthracene-9,10-dione 1-6a could change the fluorescence from light blue to yellow(6a), acetophenone regulated the fluorescence of triphenylamine from blue to light green (6b) and the installation of anisole to perylene could induce strong yellowishgreen emission (6c)(in chloroform).

Subsequently, the EMM-SMC reaction was applied in the synthesis with solubility issues. Aryl halides with a solubility of $10^{-2}-10^{-3} \mathrm{M}$, designated "slightly soluble" in the U.S. Pharmacopoeia ${ }^{72}$ often require a large amount of solvent in homogeneous solution based reactions, leading to the cross-coupling very 
slow and inefficient. To our delight, the transformation of the insoluble aryl halides could proceed efficiently under EMM conditions without neither molecular dispersant nor heating, delivering the corresponding products in good yields (7a: 74\%, 7b:87\%, 7c: 63\%). On the other hand, the target molecules with poor solubility could also be furnished under the standard conditions, providing $7 \mathrm{~d}$ in $66 \%$ and 7 e in $85 \%$ yields.

Table 5. Synthesis of Bioactive Molecules via EMM-SMC. ${ }^{a}$

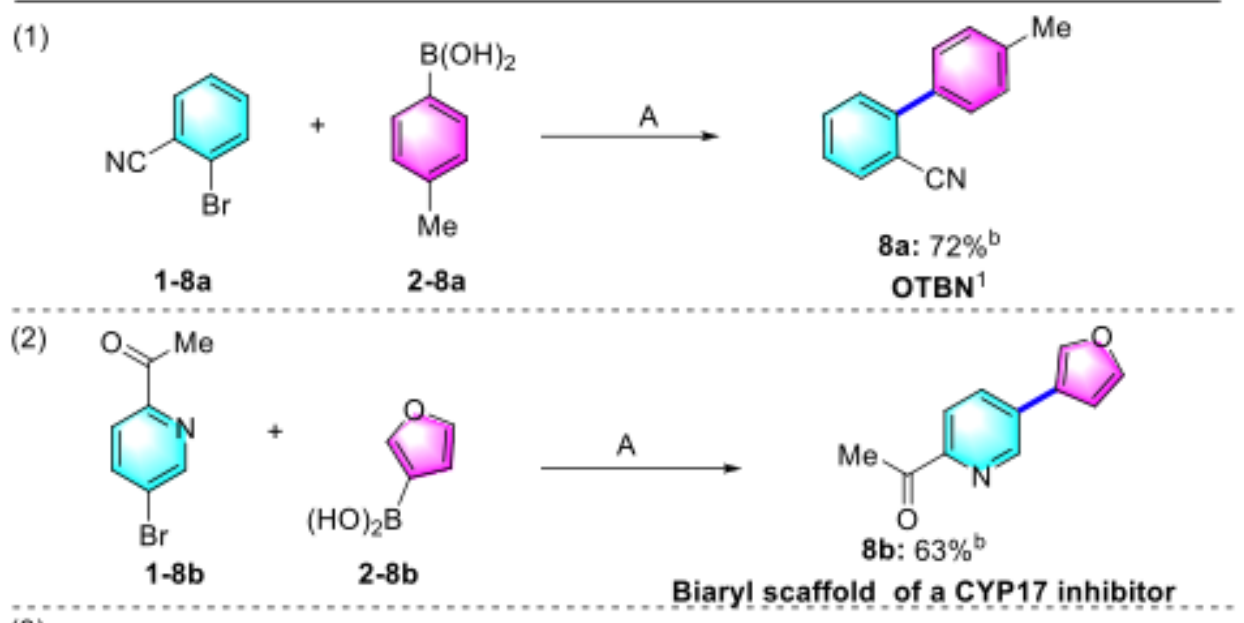

(3)
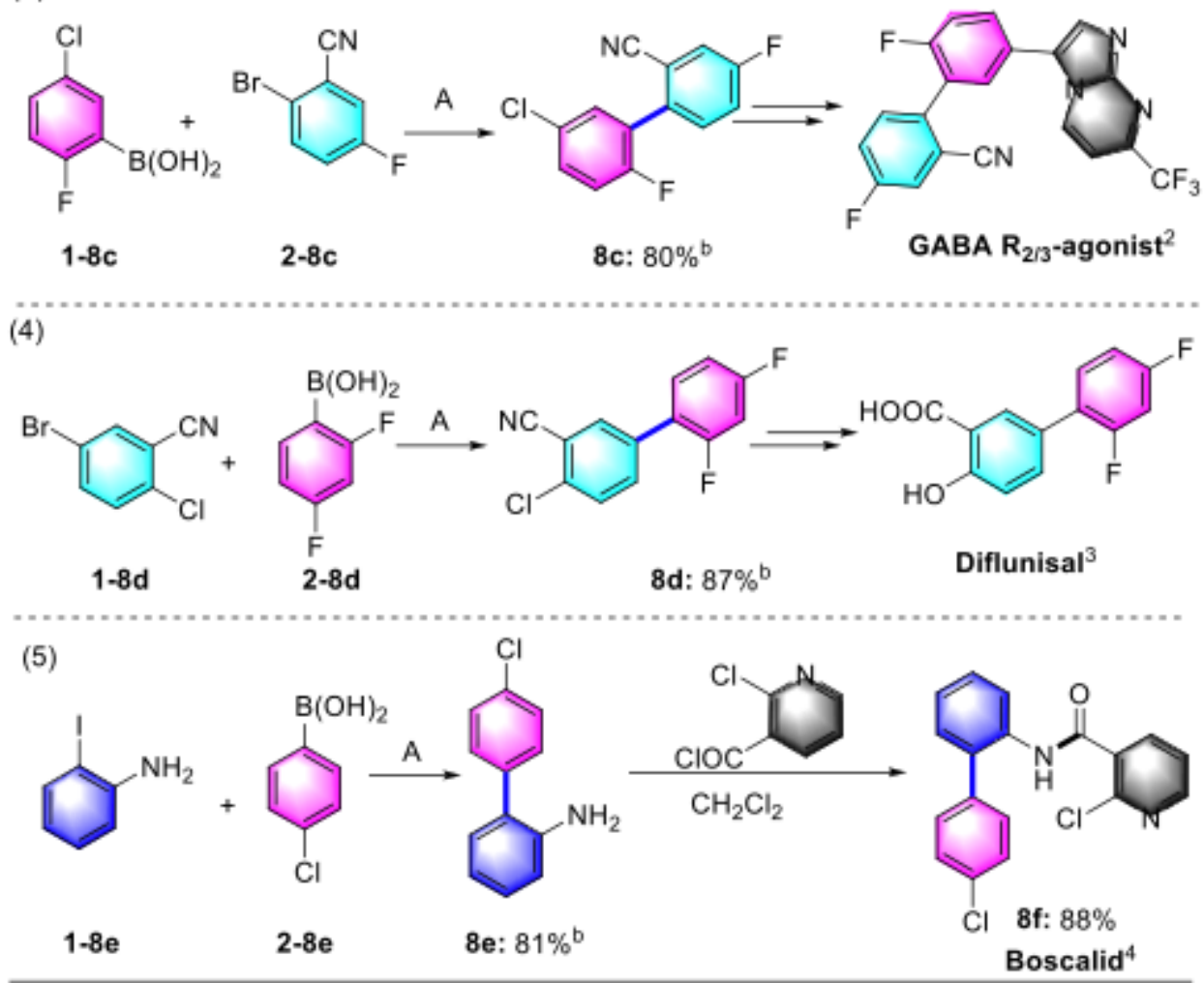

aIsolated yield. bConditions A: 1-8 (1.0 mmol $)$, 2-8(1.2 mmol), $\mathrm{Pd}(\mathrm{dppf}) \mathrm{Cl}_{2}$ (0.0005 mmol), DavePhos (0.00075 mmol), KF (3.0 $\mathrm{mmol})$, in a flat bottom flask $(10 \mathrm{~mL})$ with ferromagnetic rods $(5 \mathrm{~g})$, EMM, $50 \mathrm{~Hz}, 3 \mathrm{~h}$. 
Furthermore, we examined the EMM-SMC reaction in the synthesis of bioactive molecules. The $o$-tolyl benzonitrile (OTBN) utilized in the synthesis of six different sartan-class drugs for the treatment of hypertension, could be efficiently achieved via EMM-SMC reaction of 2-bromobenzonitrile with $p$ tolylboronic acid (8a: 72\%) (Eq 1, Table 5). ${ }^{73}$ A furan-containing pharmaceutical intermediates 8b (CYP17 inhibitor) were successfully prepared in $63 \%$ yield (Eq 2, Table 5). ${ }^{74}$ The key intermediate $8 \mathrm{c}$ for GABA R2/3-agonist which was used for treating anxiety, was furnished efficiently under the standard conditions (8c: $80 \%)$ (Eq 3, Table 5). Diflunisal is a non-steroidal drug with analgesic, anti-inflammatory and antipyretic properties similar to aspirin. The biaryl scafford 8d, core of diflunisal, was efficiently prepared by using 5-bromo-2-chlorobenzonitrile and (2,4-difluorophenyl)boronic acid (8d: 87\%) (Eq 4, Table 5).

The nicotinamide fungicide Boscalid which was developed by BASF, exhibit a broad spectrum of bactericidal activity and efficacy against various of fungal disease. ${ }^{75-77}$ One of the industrial production routes is a two-step process using 2-iodophenylaniline, 4-chlorophenylboronic acid and 2-chloronicotinyl chloride. However, the high cost of 2-iodophenylaniline led to this route less competitive. Through the EMM-SMC reaction, inexpensive 2-bromoaniline, instead of 2-iodophenylaniline, could work efficiently to provide the boscalid in $71 \%$ yield for two steps Eq 5, Table 5).

To further explore the potential of this methodology, gram-scale operation was practically performed on $10 \mathrm{mmol}$ for the synthesis of 1-(4'-methoxy-[1,1'-biphenyl]-4-yl)ethan-1-one 3a with a significant industrial value in $92 \%$ isolated yield $(2.08 \mathrm{~g})$ (Scheme1).

With regard to this solid-state EMM-SMC reaction, the ultra-low palladium loading and highly efficient transformation of this strategy cause our interest to the reaction mechanism. Generally, the classic SMC reaction catalyzed by palladium/phosphine ligand is quite sensitive to oxygen, that's why inert gas protection is necessary; however, this procedure proceeded efficiently under air conditions with only 0.05 mol\% palladium loading. Notably, Hartwig et al. reported a palladium(I) dimer catalyzed SMC which is airstable and could be finished in 15 min. ${ }^{78}$ Recently, Schoenebeck group reported a series of work on palladium(I) dimer catalyzed cross-coupling reactions which exhibited excellent catalytic reactivity. ${ }^{79-85}$ Inspired by the pioneer work and the performance of this system, we wonder if it is possible to generate a precatalyst palladium(I) dimer in situ under EMM conditions. So we utilized XPS analysis to characterize the changes of valence state of palladium during the reaction (Figure 2). In the blank sample, $\mathrm{Pd}(\mathrm{OAc})_{2}$ (1.0 equiv.) was mixed with DavePhos (1.5 equiv.), and the XPS analysis of Pd $3 d_{5 / 2}$ shows the binding energy value of $336.93 \mathrm{eV}$, which is assigned to $\mathrm{Pd}(\mathrm{II})$ species (Figure 2a). When substrates $1 \mathrm{a}$ and $2 \mathrm{a}$ were subjected to the catalyst system for $10 \mathrm{~min}$, a new curve shows that the binding energy value of Pd $3 d_{5 / 2}$ shifts from $336.93 \mathrm{eV}\left(\mathrm{Pd}^{2+}\right)$ to $336.06 \mathrm{eV}$ which is assigned to $\mathrm{Pd}^{+} 3 \mathrm{~d}_{5 / 2}$ (Figure $2 \mathrm{~b}$, curve in light green). Meanwhile, the binding energy value of $\mathrm{Pd}^{0} 3 \mathrm{~d}_{5 / 2}$ at $335.5 \mathrm{eV}$ was also detected (Figure $2 \mathrm{~b}$, curve in pink). After the reaction was finished, the signal of binding energy value of $\mathrm{Pd}^{0} 3 \mathrm{~d}_{5 / 2}(335.5 \mathrm{eV})$ was enhanced obviously indicating the increasing of $\mathrm{Pd}^{0}$ (Figure 2c, curve in pink). These results strongly indicated $\mathrm{Pd}^{\text {"l }}$ complex was reduced to $\mathrm{Pd}^{\prime}$ during the transformation, however, we could not confirm if a palladium(I) dimer was involved or not. Although we performed a series of control experiments to capture 
some radical intermediates using free radical scavenger or isolate key intermediates, the highly reaction efficiency and ultra-low catalyst loading made it difficult to obtain more information, and the mechanism is still unclear.

Very recently, Galán-Mascarós ${ }^{86}$, Kicińskii ${ }^{87}$, Chatenet/Carrey ${ }^{88}$ and Ding ${ }^{89}$ successively demonstrated that an external magnetic field could significantly enhance the catalytic activity of catalysts in the oxygen reduction reaction (ORR) and oxygen-evolution reactions (OER). Galán-Mascarós found a trend with a negligible effect for non-magnetic catalysts but maximum enhancement for highly magnetic ones in the magnetic nature of the catalysts. In this catalysis, the catalytic activity of possibly involved magnetic palladium $(I)$ complex might be enhanced under the magnetic field via promoting the electron transfer. To investigate the effect of magnetic field to the SMC reaction, three control experiments were performed in toluene at different temperature without magnetic field (Table 6). Under the EMM conditions for 1 hour, 3a was isolated in $99 \%$ yield (Entry 1), however, the yields decreased sharply when the reaction were conducted in toluene. Only $27 \%$ yield of 3 a was obtained with $66 \% 1$ a recovered at room temperature (Entry 2). When the reaction was heated to even $80^{\circ} \mathrm{C}$, the coupling reaction could not be finished with $21 \%$ of 1 a recovered (Entries $2-4$ ). Notably, the reactions performed in toluene generated homocoupling products $3 a-2$ in $7 \%, 10 \%, 12 \%$ respectively. However, the homocoupling was totally suppressed under the EMM conditions. All of these results indicated that the EMM conditions could enhance the catalytic activity significantly.

Table 6. The Comparison of EMM with Solvent-based Reaction.

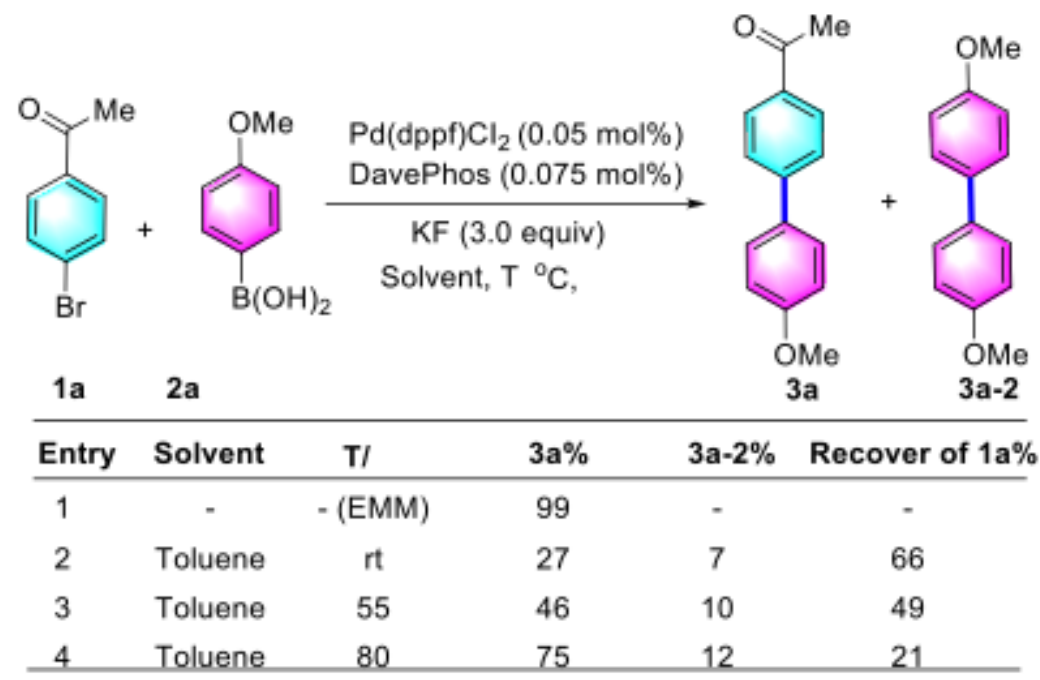

asolated yield. bConditions A: 1-8(1.0 mmol $), 2-8(1.2 \mathrm{mmol})$, $\mathrm{Pd}(\mathrm{dppf}) \mathrm{Cl}_{2}$ (0.0005 mmol), DavePhos (0.00075 mmol), KF (3.0 $\mathrm{mmol})$, in a flat bottom flask $(10 \mathrm{~mL})$ with ferromagnetic rods $(5 \mathrm{~g})$, EMM, $50 \mathrm{~Hz}, 3 \mathrm{~h}$.

In summary, we have developed the first EMM promoted solid-state SMC reaction using a catalytic system consisting of $\mathrm{Pd}(\mathrm{dppf}) \mathrm{Cl}_{2} /$ DavePhos. While few previous ball-milling palladium-catalyzed solidstate coupling reactions have been reported, the substrate scope limitation, low conversion rates, using of 
molecular dispersants and high palladium loading significantly limit their application. Under this EMM system, the solid-state SMC could be successfully achieved using ultra-low catalyst loading $(0.05 \mathrm{~mol} \%)$ without any molecular dispersants. This strategy shows broad substrate scope, good functional groups tolerance and efficient gram-scale synthesis. Furthermore, its utility was exemplified in the modification of photoluminescence molecules, cross-coupling of slightly soluble compound and synthesis of several important bioactive molecules. Then, the XPS analyses on the oxidation state changes of palladium catalyst suggest the involvement of $\mathrm{Pd}^{\prime}$ intermediate which might be the active catalytic species. Compared with the EMM-SMC, solution-based conditions afforded relative lower yields within same reaction time; even so, homocoupling byproduct was also detected. Although the results indicate EMM system exhibit excellent catalytic efficiency, the effect of magnetic field is still unclear. Finally, we anticipate that this solvent-free solid-state EMM-SMC could be developed into industrially attractive and environmentally friendly routes, and the EMM system developed in this study could unlock broad areas of chemical space for solvent-free solid-state metal-catalyzed syntheses of valuable targets in various scientific fields.

Data availability

The processed experimental data generated in this study have been deposited in the figshare database at:

\section{Declarations}

Acknowledgements

We gratefully acknowledge the National Natural Science Founda-tion of China (22078178), Youth Innovative Talents Attracting and Cultivating Plan of Colleges and Universities in Shandong Province.

Author contributions

H.L. and Z.Z. designed the research. L. Z. and Y. D. performed the research. Q. L., D.Z. and L.C. analysed the data, and X.L. and Y.L. wrote the paper.

Competing interests

The authors declare no competing interests.

Additional information

Supporting information. The online version contains supplementary materialm available at:

Correspondence and requests for materials should be addressed to H. L or Z. Z. 
Peer review information

Reprints and permission information is available at:

Publisher's note Springer Nature remains neutral with regard to jurisdictional claims in published maps and institutional affiliations.

\section{References}

1. Clarke, C. J., Tu, W. C., Levers O., Bröhl, A., Hallett, J. P. Green and sustainable solvents in chemical processes. Chem. Rev. 118, 747-800 (2018).

2. Wilson, K. L., Murray, J., Sneddon, H. F., Wheelhouse, K. M. P. Watson, A. J. B. Connecting the dots: Method development using sustainable solvents. Chem. 3, 365-368 (2017).

3. Sheldon, R. A. Green solvents for sustainable organic synthesis: state of the art. Green Chem. 7, 267278 (2005).

4. Constable, D. J. C., Jimenez-Gonzalez, C. Henderson, R. K. Perspective on solvent use in the pharmaceutical industry. Org. Process Res. Dev. 2007, 11, 133-137.

5. Clark, J. H., Tavener, S. J. Alternative solvents: shades of green. Org. Process Res. Dev. 11, 149-155 (2007).

6. DeSimone, J. M. Practical approaches to green solvents. Science 297, 799-803 (2002).

7. An estimated $6 \%$ of total US energy use is due to distillation generally Emerson Process Management, http://www.emersonprocessxperts.com/archives/2010/04/reducing_distil.html.

8. Tanaka, K. Solvent-Free Organic Synthesis, 2nd revised edn. (Wiley-VCH, Weinheim 2009).

9. Toda, F. Organic Solid-State Reactions (Springer, Berlin Heidelberg 2004).

10. Toda, F. Solid state organic chemistry: Efficient reactions, remarkable yields, and stereoselectivity. Acc. Chem. Res. 28, 480-486 (1995).

11. Tanaka, K., Toda, F. Solvent-free organic synthesis. Chem. Rev. 100, 1025-1074 (2000).

12. Toda, F. Organic solid-state reactions, ed. (Springer 2004).

13. Toda, F. Solid State Organic Chemistry: Efficient Reactions, Remarkable Yields, and Stereoselectivity. Acc. Chem. Res. 28, 480-486 (1995).

14. Suslick, K. S. Mechanochemistry and sonochemistry: concluding remarks. Faraday Discuss 170, 411-422 (2014).

15. Boulatov, R. Polymer Mechanochemistry (Berlin: Springer, 2015).

16. Friščić, T. J. New opportunities for materials synthesis using mechanochemistry. Chem. 20, 75997605 (2010).

17. Zhu, S., Li, F., Wang, G. W. Mechanochemistry of fullerenes and related materials. Chem. Soc. Rev. 42, 7535-7570 (2013). 
18. Baláž, P. Mechanochemistry in minerals engineering. In Mechanochemistry in nanoscience and minerals engineering. (Springer, Berlin, Heidelberg, 2008; pp. 257-296).

19. James, S. L., Adams, C. J., Bolm, C., Braga, D., Collier, P., Frišić, T.; Grepioni, F., Harris, K. D. M., Hyett, G., Jones, W., Krebs, A.; Mack, J., Maini, L., Orpen, A. G., Parkin, I. P., Shearouse, W. C., Steed, J. W., Waddell, D. C. Mechanochemistry: opportunities for new and cleaner synthesis. Chem. Soc. Rev. 41, 413-447 (2012).

20. Wang, G. W. Mechanochemical organic synthesis. Chem. Soc. Rev. 42, 7668-7700 (2013).

21. Do, J. L., Frišić, T. Mechanochemistry: a force of synthesis. ACS Cent. Sci. 3, 13-19 (2017).

22. Hernández, J. G., Bolm, C. Altering product selectivity by mechanochemistry. J. Org.Chem. 82, 40074019 (2017).

23. Tan, D., Frišić, T. Mechanochemistry for organic chemists: an update. Eur. J. Org. Chem. 2018, 18-33 (2018).

24. Howard, J. L., Cao, Q., Browne, D. L. Mechanochemistry as an emerging tool for molecular synthesis: what can it offer? Chem. Sci. 9, 3080-3094 (2018).

25. Andersen, J., Mack, J. Mechanochemistry and organic synthesis: from mystical to practical. Green Chem. 20, 1435-1443 (2018).

26. Bolm, C., Hernández, J. G. Mechanochemistry of gaseous reactants. Angew. Chem., Int. Ed. 58, 3285-3299 (2019).

27. Gomollón-Bel, F. Ten Chemical Innovations That Will Change Our World: IUPAC identifies emerging technologies in Chemistry with potential to make our planet more sustainable. Chem. Int. 41, 12-17 (2019).

28. Friščić, T., Halasz, I., Štrukil, V., Eckert-Maksic, M., Dinnebier, R. E. Clean and efficient synthesis using mechanochemistry: coordination polymers, metal-organic frameworks and metallodrugs. Croatica chemica acta 85, 367-378 (2012).

29. Hernández, J. G. C - H bond functionalization by mechanochemistry. Chem. Eur. J. 23, 1715717165 (2017).

30. Metro, T. X. M., Martinez, J., Lamaty, F. 1,1-Carbonyldiimidazole and mechanochemistry: a shining green combination. ACS Sustainable Chem. Eng. 5, 9599-9602 (2017).

31. Achar, T. K., Bose, A., Mal, P. Mechanochemical synthesis of small organic molecules. Beilstein J. Org. Chem. 13 1907-1931 (2017).

32. Do, J. L., Friščić, T. Chemistry 2.0: developing a new, solvent-free system of chemical synthesis based on mechanochemistry. Synlett 28, 2066-2092 (2017).

33. Eguaogie, O., Vyle, J. S., Conlon, P. F., Gîlea, M. A., Liang, Y. Mechanochemistry of nucleosides, nucleotides and related materials. Beilstein J. Org. Chem. 14, 955-970 (2018).

34. Rightmire. N. R., Hanusa, T. P. Advances in organometallic synthesis with mechanochemical methods. Dalton Trans. 45, 2352-2362 (2016). 
35. Leonardi, M., Villacampa, M., Menéndez, J. C. Multicomponent mechanochemical synthesis. Chem. Sci. 9, 2042-2064 (2018).

36. Xu, C.; De, S., Balu, A. M., Ojeda, M., Luque, R. Mechanochemical synthesis of advanced nanomaterials for catalytic applications. Chem. Commun. 51, 6698-6713 (2015).

37. Tan, D., Loots, L., Friščić, T. Towards medicinal mechanochemistry: evolution of milling from pharmaceutical solid form screening to the synthesis of active pharmaceutical ingredients (APIs). Chem. Commun. 52, 7760-7781 (2016).

38. Gečiauskaitè, A. A., García, F. Main group mechanochemistry. Beilstein J. Org. Chem. 13, 2068-2077 (2017).

39. Munoz-Batista, M. J., Rodriguez-Padron, D., Puente-Santiago, A. R., Luque, R. Mechanochemistry: toward sustainable design of advanced nanomaterials for electrochemical energy storage and catalytic applications. ACS Sustainable Chem. Eng. 6, 9530-9544 (2018).

40. Colacino, E., Carta, M., Pia, G., Porcheddu, A., Ricci, P. C., Delogu, F. Processing and investigation methods in mechanochemical kinetics. ACS omega 3, 9196-9209 (2018).

41. Tan, D., García, F. Main group mechanochemistry: from curiosity to established protocols. Chem. Soc. Rev. 48, 2274-2292 (2019).

42. Schneider, F., Szuppa, T., Stolle, A., Ondruschka, B., Hopf, H. Energetic assessment of the SuzukiMiyaura reaction: a curtate life cycle assessment as an easily understandable and applicable tool for reaction optimization. Green Chem. 11, 1894-1899 (2009).

43. Hernández, J. G., Friščić, T. Metal-catalyzed organic reactions using mechanochemistry. Tetrahedron Letters 56, 4253-4265 (2015).

44. Diederich, F., Stang, P. J. Metal-catalyzed cross-coupling reactions (John Wiley \& Sons. 2008).

45. Miyaura, N., Suzuki, A. Palladium-catalyzed cross-coupling reactions of organoboron compounds. Chem. Rev. 95, 2457-2483 (1995).

46. Lennox, A. J. J., Lloyd-Jones, G. C. Selection of boron reagents for Suzuki-Miyaura coupling. Chem. Soc. Rev. 43, 412-443 (2014).

47. Martin, R., Buchwald, S. L. Palladium-catalyzed Suzuki-Miyaura cross-coupling reactions employing dialkylbiaryl phosphine ligands. Acc. Chem. Res. 41, 1461-1473 (2008).

48. Schneider, N., Lowe, D. M., Sayle, R. A., Tarselli, M. A., Landrum, G. A. Big data from pharmaceutical patents: a computational analysis of medicinal chemists' bread and butter. J. Med. Chem. 59, 43854402 (2016).

49. Wu, X., Anbarasan, P., Neumann, H., Beller, M. From noble metal to Nobel prize: palladium-catalyzed coupling reactions as key methods in organic synthesis. Angew. Chem. Int. Ed. 49, 9047-9050 (2010).

50. Suzuki, A. Cross-coupling reactions of organoboranes: an easy way to construct C-C bonds (Nobel Lecture). Angew. Chem. Int. Ed. 50, 6723-6737 (2011). 
51. Miyaura, N., Yanagi, T., Suzuki, A. The palladium-catalyzed cross-coupling reaction of phenylboronic acid with haloarenes in the presence of bases. Synthetic Communications 11, 513-519 (1981).

52. Miyaura, N. Cross-coupling Reaction (Springer, 2002).

53. Cravotto, G., Garella, D., Tagliapietra, S., Stolle, A., Schüßler, S., Leonhardt, S. E., Ondruschka, B. Suzuki cross-couplings of (hetero) aryl chlorides in the solid-state. New J. Chem. 36, 1304-1307 (2012).

54. Schneider, F., Ondruschka, B. Mechanochemical Solid-State Suzuki Reactions Using an In Situ Generated Base. Chem. Sus. Chem. 1, 622-625 (2008).

55. Nielsen, S. F.; Peters, D., Axelsson, O. The Suzuki reaction under solvent-free conditions. Synthetic Communications, 30, 3501-3509 (2000).

56. Klingensmith, L. M., Leadbeater, N. E. Ligand-free palladium catalysis of aryl coupling reactions facilitated by grinding. Tetrahedron letters 44, 765-768 (2003).

57. Schneider, F., Stolle, A., Ondruschka, B., Hopf, H. The Suzuki-Miyaura reaction under mechanochemical conditions. Org. Process Res. Dev. 13, 44-48 (2009).

58. Jiang, Z. J., Li, Z. H., Yu, J. B., Su, W. K. Liquid-assisted grinding accelerating: Suzuki-Miyaura reaction of aryl chlorides under high-speed ball-milling conditions. J. Org. Chem. 81, 10049-10055 (2016).

59. Braga, D., D'Addari, D., Polito, M., Grepioni, F. Mechanically induced expeditious and selective preparation of disubstituted pyridine/pyrimidine ferrocenyl complexes. Organometallics 23, 2810 2812 (2004).

60. Schneider, F., Szuppa, T., Stolle, A., Ondruschka, B., Hopf, H. Energetic assessment of the SuzukiMiyaura reaction: a curtate life cycle assessment as an easily understandable and applicable tool for reaction optimization. Green Chem. 11, 1894-1899 (2009).

61. Bernhardt, F., Trotzki, R., Szuppa, T., Stolle, A., Ondruschka, B. Solvent-free and time-efficient SuzukiMiyaura reaction in a ball mill: the solid reagent system $\mathrm{KF}-\mathrm{Al}_{2} \mathrm{O}_{3}$ under inspection. Beilstein J. Org. Chem. 6, 7 (2010).

62. Seo, T., Ishiyama, T., Kubota, K., Ito, H. Solid-state Suzuki-Miyaura cross-coupling reactions: olefinaccelerated C-C coupling using mechanochemistry. Chem. Sci. 10, 8202-8210 (2019).

63. Kubota, K., Seo, T., Koide, K., Hasegawa, Y., Ito, H. Olefin-accelerated solid-state C-N cross-coupling reactions using mechanochemistry. Nature commun. 10, 1-11 (2019).

64. Seo, T., Toyoshima, N., Kubota, K., Ito, H. Tackling Solubility Issues in Organic Synthesis: Solid-State Cross-Coupling of Insoluble Aryl Halides. J. Am. Chem. Soc. 143, 6165-6175 (2021).

65. Styła, Sebastian. Analysis of temperature distribution in electromagnetic mill. Przegląd Elektrotechniczny. 92, 103-106 (2016).

66. Abo-Dahab, S. M., Abd-Alla, A. Electromagnetic Field and Three-Phase-Lag in a Compressed Rotating Isotropic Homogeneous Micropolar Thermo-Viscoelastic Half-Space. Authorea Preprints (2020). 
67. Wołosiewicz-Głąb, M., Ogonowski, S., Foszcz, D. Construction of the electromagnetic mill with the grinding system, classification of crushed minerals and the control system. IFAC-PapersOnLine 49, 67-71 (2016).

68. Wołosiewicz-Głąb, M., Foszcz, D., Ogonowski, S. Design of the electromagnetic mill and the air stream ratio model. IFAC-PapersOnLine 50, 14964-14969 (2017).

69. Ogonowski, S., Wołosiewicz-Głąb, M., Ogonowski, Z., Foszcz, D., Pawełczyk, M. Comparison of wet and dry grinding in electromagnetic mill. Minerals 8, 138 (2018).

70. Litti, Y., Kovalev., D, Kovalev, A., Katraeva, I., Russkova1, Y., Nozhevnikova, A. Increasing the efficiency of organic waste conversion into biogas by mechanical pretreatment in an electromagnetic mill. $J$. Phys.:Conf. Ser. 1111, 012013 (2018).

71. Styła, S. A new grinding technology using an electromagnetic mill-testing the efficiency of the process. ECONTECHMOD: An International Quarterly Journal on Economics of Technology and Modelling Processes. 6, 81-88 (2017).

72. Pharmacopeia of the United States of America, 32nd revision, and the National Formulary, 27th ed. (US Pharmacopeia: 2009).

73. O’Brien, H. M., Manzotti, M., Abrams, R. D., Elorriaga, D., Sparkes, H. A., Davis, S. A., Bedford, R. B. Ironcatalysed substrate-directed Suzuki biaryl cross-coupling. Nature Catalysis 1, 429-437 (2018).

74. Magano, J., Dunetz, J. R. Large-scale applications of transition metal-catalyzed couplings for the synthesis of pharmaceuticals. Chem. Rev. 111, 2177-2250 (2011).

75. Eicken, K. et al. Anilide derivatives and their use to combat Botrytis. European patent: 0545099 (1993).

76. Eicken, K. et al. Bisphenylamides. German patent: 19531813 (1997).

77. Torborg, C., Beller, M. Recent applications of palladium-catalyzed coupling reactions in the pharmaceutical, agrochemical, and fine chemical industries. Adv. Synth. Catal. 351, 3027-3043 (2009).

78. Stambuli, J. P., Kuwano, R., Hartwig, J. F. Unparalleled rates for the activation of aryl chlorides and bromides: Coupling with amines and boronic acids in minutes at room temperature. Angew. Chem. Int. Ed. 41, 4746-4748 (2002).

79. Johansson Seechurn, C. C. C., Sperger, T., Scrase, T. G., Schoenebeck, F., Colacot, T. J. Understanding the unusual reduction mechanism of $\mathrm{Pd}(\mathrm{II})$ to $\mathrm{Pd}(\mathrm{I})$ : uncovering hidden species and implications in catalytic cross-coupling reactions. J. Am. Chem. Soc. 139, 5194-5200 (2017).

80. Proutiere, F., Aufiero, M., Schoenebeck, F. Reactivity and stability of dinuclear $\operatorname{Pd}(I)$ complexes: Studies on the active catalytic species, insights into precatalyst activation and deactivation, and application in highly selective cross-coupling reactions. J. Am. Chem. Soc. 134, 606-612 (2012).

81. Kalvet, I., Magnin, G., Schoenebeck, F. Rapid Room-Temperature, Chemoselective C-C Coupling of Poly (pseudo) halogenated Arenes Enabled by Palladium(I) Catalysis in Air. Angew. Chem. Int. Ed. 56, 1581-1585 (2017). 
82. Mendel, M., Kalvet, I., Hupperich, D., Magnin, G., Schoenebeck, F. Site-Selective, Modular Diversification of Polyhalogenated Aryl Fluorosulfates $\left(\mathrm{ArOSO}_{2} \mathrm{~F}\right)$ Enabled by an Air-Stable $\mathrm{Pd}(\mathrm{I})$ Dimer. Angew. Chem. Int. Ed. 59, 2115-2119 (2020).

83. Kalvet, I., Deckers, K., Funes-Ardoiz, I., Magnin, G., Sperger, T., Kremer, M., Schoenebeck, F. Selective ortho-Functionalization of Adamantylarenes Enabled by Dispersion and an Air-Stable Palladium(I) Dimer. Angew. Chem. 132, 7795-7799 (2020).

84. Kundu, G., Sperger, T., Rissanen, K.; Schoenebeck, F. A Next-Generation Air-Stable Palladium(I) Dimer Enables Olefin Migration and Selective C - C Coupling in Air. Angew. Chem. 132, 22114-22118 (2020).

85. Keaveney, S. T., Kundu, G., Schoenebeck, F. Modular Functionalization of Arenes in a Triply Selective Sequence: Rapid $\mathrm{C}\left(s p^{2}\right)$ and $\mathrm{C}\left(s p^{3}\right)$ Coupling of $\mathrm{C}-\mathrm{Br}, \mathrm{C}-\mathrm{OTf}$, and $\mathrm{C}-\mathrm{Cl}$ Bonds Enabled by a Single Palladium(I) Dimer. Angew. Chem. Int. Ed. 57, 12573-12577 (2018).

86. Garcés-Pineda, F. A., Blasco-Ahicart, M., Nieto-Castro, D., López, N., Galán-Mascarós, J. R. Direct magnetic enhancement of electrocatalytic water oxidation in alkaline media. Nature Energy 4, 519525 (2019).

87. Kiciński, W., Sęk, J. P., Matysiak-Brynda, E. Miecznikowski, K., Donten, M., Budner, B., Nowicka, A. M. Enhancement of PGM-free oxygen reduction electrocatalyst performance for conventional and enzymatic fuel cells: The influence of an external magnetic field. Applied Catalysis B: Environmental, 258, 117955 (2019).

88. Niether, C., Faure, S., Bordet, A., Deseure, J., Chatenet, M., Carrey, J., Chaudret, B., Rouet, A. Improved water electrolysis using magnetic heating of FeC-Ni core-shell nanoparticles. Nature Energy 3, 476483 (2018).

89. Yan, J., Wang, Y., Zhang, Y., Xia, S., Yu, J., Ding, B. Direct magnetic reinforcement of electrocatalytic ORR/OER with electromagnetic induction of magnetic catalysts. Adv. Mater. 33, 2007525 (2021).

\section{Scheme}

Scheme 1 is provided in the Supplementary Files section.

\section{Figures}


A
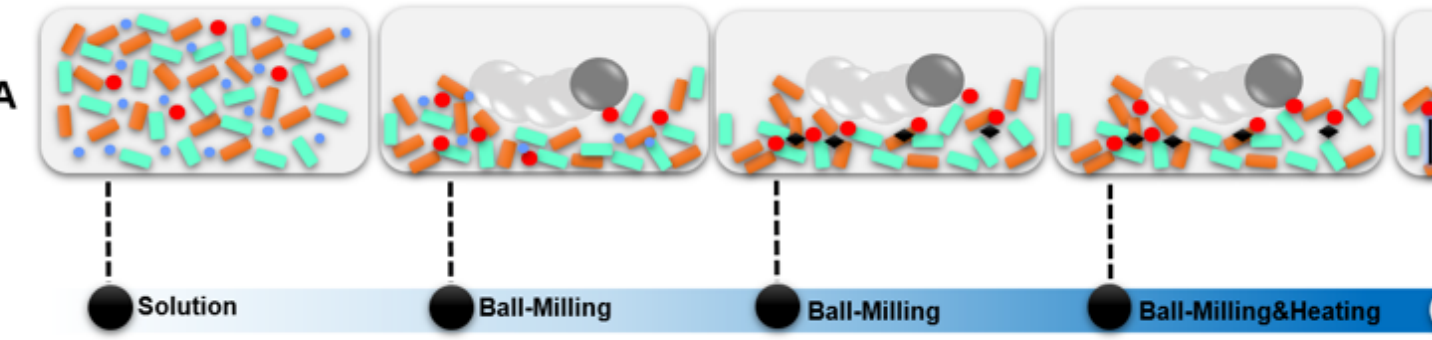

Electromagnetic Mill

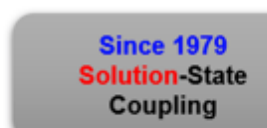

Coupling

Catalyst Solvent

Since 2000
Liquid-Assisted Grinding using Small Amount Solvent $2-20 \mathrm{~mol} \%[\mathrm{Pd}]$
Since 2019

Olefin as Molecular

Dispersants

$3 \mathrm{~mol} \%$ [Pd]
Since 2021
Olefin-Accelerated SMC
with Insoluble Aryl Halides $10 \mathrm{~mol} \%$ [Pd]
This work

No LAG or Molecular

Dispersants

$0.05 \mathrm{~mol} \%[\mathrm{Pd}]$

Olefin

Solid Reactants I

Solid Reactants II

| Ferromagnetic Rods

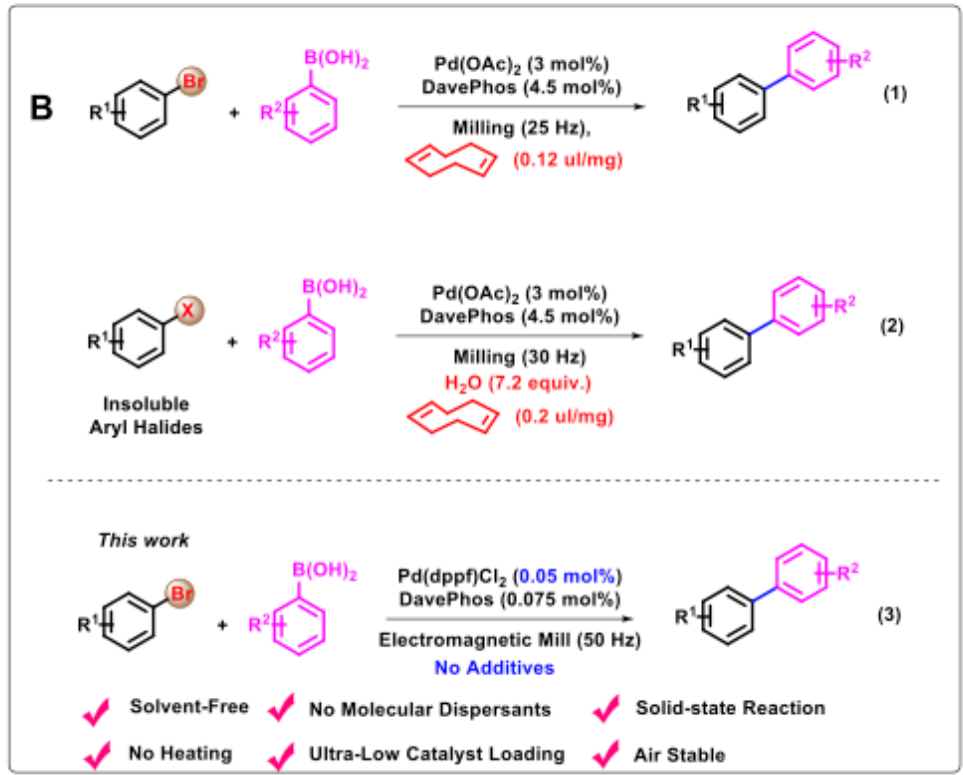

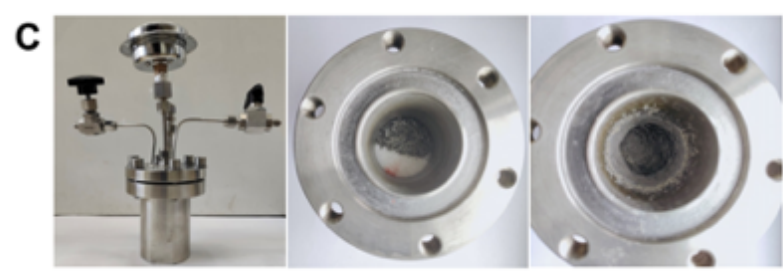

(a) Reactor

(b) Before

(c) After Electromagnetic Mill (30 min)

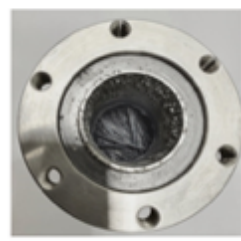

(d) Finished

(e) Reaction Mixture

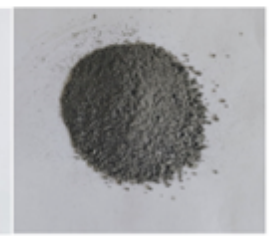

(f) Crude Product after Separation

\section{Figure 1}

Suzuki-Miyaura Cross-Coupling of Solid-state Reactants using Mechanochemistry. (A) Chronology of Suzuki-Miyaura Cross-Coupling for Solid-state Reactants. (B) Recent Progresses in SMC with Broadened Substrate Scope. (C) The appearance state of Electromagnetic Mill in a stain-less-steel milling jar. 


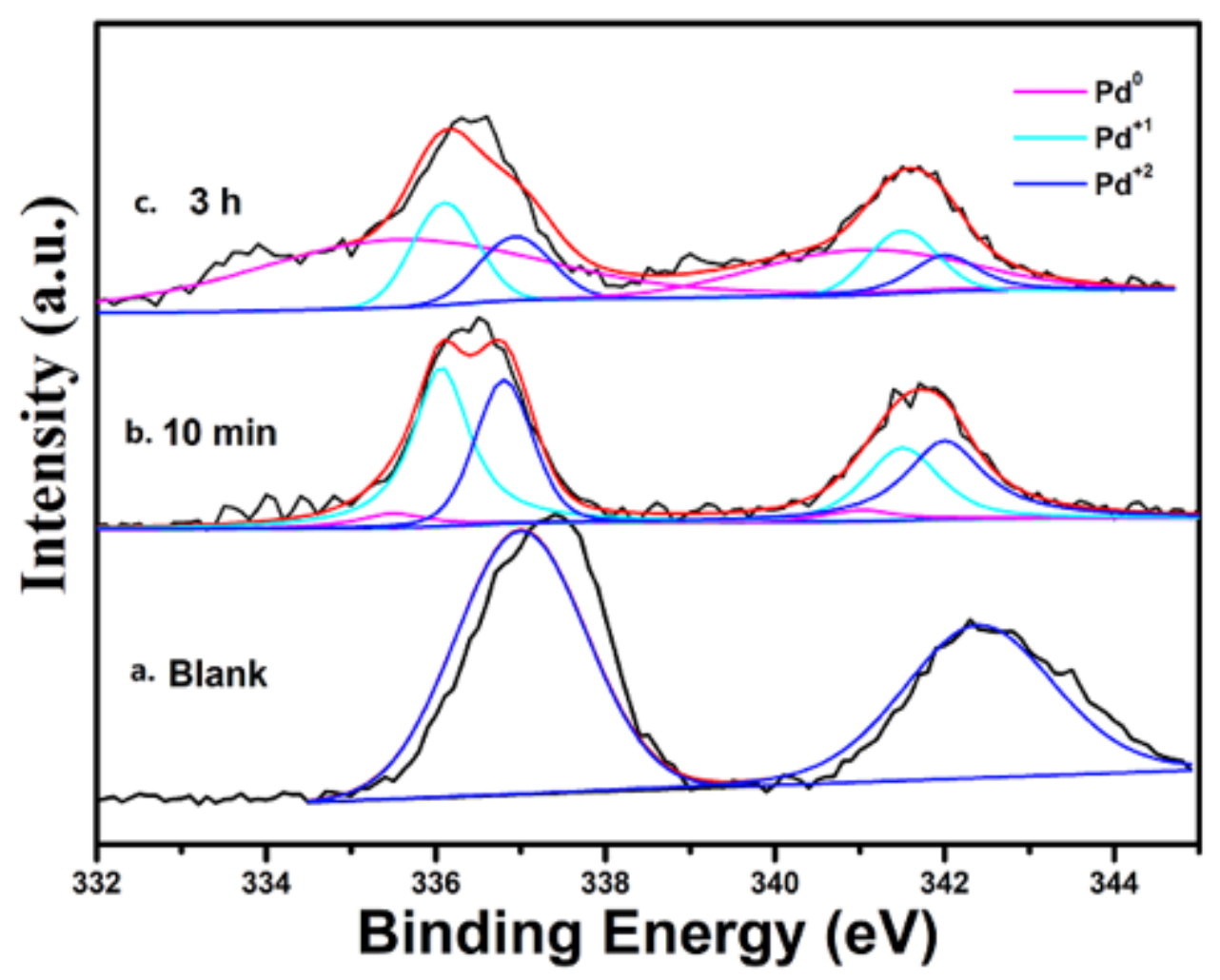

Figure 2

X-Ray Photoelectron Spectra of the Palladium Catalyst Samples. a. Blank sample: $\operatorname{Pd}(\mathrm{OAc}) 2$ mixed with DavePhos; b. Pd(OAc)2(7 mol\%)/DavePhos $(10 \mathrm{~mol} \%)$ reacted with $1 \mathrm{a}(1.0 \mathrm{mmol})$ and $2 \mathrm{a}(1.2 \mathrm{mmol})$ for $10 \mathrm{~min} ; \mathrm{c} . \mathrm{Pd}(\mathrm{OAc}) 2(7 \mathrm{~mol} \%) /$ DavePhos $(10 \mathrm{~mol} \%)$ re-acted with $1 \mathrm{a}(1.0 \mathrm{mmol})$ and $2 \mathrm{a}(1.2 \mathrm{mmol})$ for $3 \mathrm{~h}$.

\section{Supplementary Files}

This is a list of supplementary files associated with this preprint. Click to download.

- supportinginformation2021.08.31.docx

- Scheme1.png

- TOC.png 